\title{
Effect of exercise on cycle length in atrial flutter
}

\author{
Maarten P van den Berg, Harry J G M Crijns, Balázs M Szabó, Jan Brouwer, Kong I Lie
}

Department of

Cardiology,

Thoraxcentre,

University Hospital

Groningen,

Groningen,

The Netherlands

$M P$ van den Berg

H J G M Crijns

B M Szabó

J Brouwer

K I Lie

Correspondence to:

Dr M P van den Berg,

Department of Cardiology,

Thoraxcentre, University

Hospital Groningen

9700 RB, PO Box 30 001,

Groningen,

The Netherlands.

Accepted for publication

8 September 1994

\begin{abstract}
Objective-To examine the effect of exercise on cycle length in atrial flutter.

Patients -15 patients with chronic atrial flutter. Seven patients were taking digoxin and six verapamil; two were not taking medication.

Methods-All patients underwent bicycle ergometry. Flutter cycle length was measured at rest and at peak exercise.

Results-Mean flutter cycle length increased from $245 \mathrm{~ms}$ to $256 \mathrm{~ms}$ ( $P=$ $0.002)$. Six patients developed 1:1 atrioventricular conduction. Significant increases in flutter cycle length were observed irrespective of development of 1:1 atrioventricular conduction and use of digoxin and verapamil.

Conclusion-Exercise prolongs flutter cycle length. This effect would promote development of $1: 1$ atrioventricular conduction during exercise, causing inordinately high ventricular rates.

(Br Heart f 1995;73:263-264)

Keywords: atrial flutter; cycle length; exercise

Despite the frequent reference to a constant flutter cycle length in atrial flutter, ${ }^{1}$ several factors have been identified that may to some extent affect cycle length. These include changes in autonomic tone, ${ }^{23}$ cardiac filling, ${ }^{45}$ and atrial size. ${ }^{36}$ Also, drugs may alter cycle length. ${ }^{37}$ We examined the effect of exercise on flutter cycle length.
\end{abstract}

Patients and methods

The study group comprised 15 consecutive patients with chronic atrial flutter who underwent multistage, symptom limited bicycle ergometry. Their clinical characteristics are listed in the table. No patient had overt heart failure. The electrocardiograms were recorded using a computer assisted system (Marquette Electronics, Milwaukee, WI, USA). Flutter cycle length was measured at rest and at peak exercise. As it is difficult to measure accurately the length of a single flutter wave at standard paper speed $(25 \mathrm{~mm} / \mathrm{s})$ cycle length was calculated as the mean of five cycles-that is, the total duration of five successive cycles was divided by five. Effects on cycle length were also analysed relative to development of

Clinical characteristics of 15 consecutive patients with chronic atrial flutter

\begin{tabular}{ll}
\hline Characteristic & Number \\
\hline Sex (male/female) & $11 / 4$ \\
Mean (SD) (years) & $41(20)$ \\
No of patients with underlying heart disease: & \\
Hypertension & 1 \\
Dilated cardiomyopathy & 3 \\
Mitral stenosis & 1 \\
Sick sinus syndrome & 4 \\
Transposition of lung veins & 2 \\
$\quad$ "Lone" arrhythmia & 4 \\
No of patients taking: & 7 \\
Digoxin & 6 \\
Verapamil & 10 \\
Flutter type (No of patients): & 5 \\
Common & \\
Uncommon & \\
Mean (SD) echocardiographic parameters (mm): & \\
Left atrium: & $44(9)$ \\
$\quad$ Parasternal view & $62(8)$ \\
Apical view & $58(8)$ \\
Right atrium apical view & \\
$\quad$ End diastole & $53(6)$ \\
$\quad$ End systole & $37(9)$ \\
\hline
\end{tabular}

Figure 1 Electrocardiograms (leads I, aVR, V1, and V4) at rest (A) and at peak exercise (B) showing an increase in flutter cycle length (245 ms to $265 \mathrm{~ms}$ ). This was associated with development of $1: 1$ atrioventricular conduction, which caused a high ventricular rate (226 beats/minute). Cycle length was calculated by measuring the total duration of five successive cycles and dividing by five. 
Figure 2 Effect of exercise on flutter cycle length in individual patients. *Patients who developed 1:1 atrioventricular conduction.

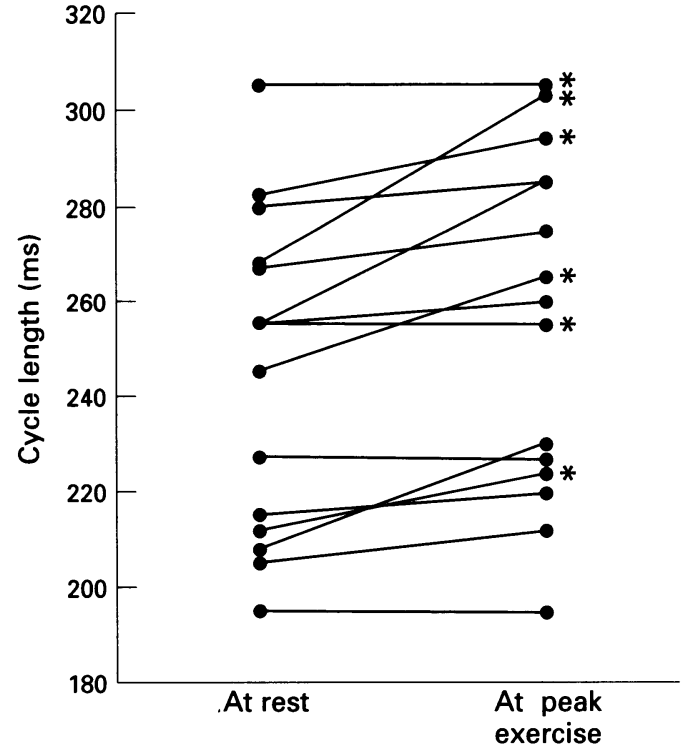

1:1 atrioventricular conduction during exercise and to use of digoxin and verapamil. For statistical analysis the Student $t$ test was used. Data are reported as means (SD).

\section{Results}

An increase in flutter cycle length was observed during exercise in 11 patients; mean values for all patients at rest and at peak exercise were 245 (33) $\mathrm{ms}$ and 256 (36) $\mathrm{ms}$, respectively $(P=0.002)$. Six patients developed 1:1 atrioventricular conduction. Figure 1 shows a representative electrocardiogram. Figure 2 shows the response to exercise in each patient. Increases in cycle length were also observed in various subgroups. In the six patients with 1:1 atrioventricular conduction during exercise, flutter cycle length increased from 262 (31) $\mathrm{ms}$ to 275 (32) $\mathrm{ms}(P=0.059)$. In the nine other patients flutter cycle length increased from 234 (31) $\mathrm{ms}$ to 243 (34) $\mathrm{ms}(\mathrm{P}=0.027)$. Flutter cycle length increased in all patients irrespective of digoxin treatment (values increased from 247 (41) $\mathrm{ms}$ to 253 (40) $\mathrm{ms}$ (P $=0.02)$ in patients taking digoxin and from 244 (27) $\mathrm{ms}$ to 259 (34) $\mathrm{ms}(P=0.017)$ in those who were not). Similarly, flutter cycle length increased irrespective of verapamil treatment; in patients taking verapamil cycle length increased from 241 (41) ms to 246 (39) $\mathrm{ms}(P=0.048)$ and in patients who were not taking verapamil cycle length increased $\begin{array}{lllll}\text { from } 248 \quad(29) \mathrm{ms} \text { to } 263 & \text { (34) } \mathrm{ms}\end{array}$ $(P=0.009)$.

\section{Discussion}

To our knowledge, this is the first study to examine explicitly the effect of exercise on flutter cycle length in patients with atrial flutter. Though our sample was small, our results show that exercise prolongs flutter cycle length. As this was an observational study and drug treatment was not randomised, no conclusions can be drawn about the underlying mechanism. None the less the data may provide important clues.

During exercise various opposing influences potentially affect cycle length. On the one hand, enhancement of sympathetic tone shortens the cycle length. ${ }^{3}$ On the other hand, withdrawal of vagal tone ${ }^{23}$ and increases in atrial filling ${ }^{45}$ and size $^{36}$ prolong cycle length. The fact that the increase in cycle length was relatively limited in patients taking digoxin suggests that diminution of vagal tone during exercise does not have an important role in changing atrial rate. Our findings suggest that the increase in flutter cycle length was mediated by haemodynamic factors-that is, changes in atrial filling and size associated with exercise. As such this would represent a form of "contraction-excitation feedback". 8 The exact underlying mechanism, however, remains to be elucidated. Increases in atrial pressure producing atrial distension may affect atrial refractoriness. ${ }^{9}{ }^{10}$ This may suffice to explain changes in cycle length in atrial flutter with a short excitable gap. However, when the excitable gap is relatively long, as is the case in most patients with atrial flutter (with a re-entrant circuit around a fixed anatomic obstacle), altered conduction velocity or changes in the perimeter of the circuit should be involved. ${ }^{11}$

Our findings may have clinical implications as patients with a long flutter cycle length are at risk of developing 1:1 atrioventricular conduction, which causes inordinately high ventricular rates. This has been shown for patients receiving antiarrhythmic drugs that prolong cycle length (foremost class Ic agents). ${ }^{12}$ Such patients are especially susceptible to developing 1:1 atrioventricular conduction during exercise as sympathetic activation facilitates atrioventricular conduction. In addition, our results suggest that exercise may also increase the risk of developing rapid atrioventricular conduction by prolonging cycle length.

1 Lewis T. Observations upon flutter and fibrillation. I. The regularity of clinical auricular flutter. Heart 1920;7: 127-30

2 Lewis T, Drury AN, Bulger HA. Observations upon flutter and fibrillation. VII. The effects of vagal stimulation. Heart 1921;8:141-70.

3 Boyden PA. Effects of pharmacologic agents on induced atrial flutter in dogs with right atrial enlargement. f Cardiovasc Pharmacol 1986;8:170-7.

4 Waxman MB, Yao L, Cameron DA, Kirsh JA. Effects of posture, Valsalva manoeuver and respiration on atrial posture rate: an effect mediated through cardiac volume. f Am Coll Cardiol 1991;17:1545-52.

5 Waxman MB, Kirsh JA, Yao L, Cameron DA, Asta JA. Slowing of the atrial flutter rate during $1: 1$ atrioventricuthrough atrial pressure and volume. $f$ Cardiovasc Electrophysiol 1992;3:544-57.

6 Rytand DA, Onesti SJ, Barns DL. The atrial rate in patients with atrial flutter. A relationship between atrial enlargement and slow rate. Stanford Medical Bulletin 1958;16:169-76.

7 Crijns HJGM, de Langen CDJ, Grandjean JG, Bel KJ, Ebels T, Lie KI, Wesseling H. Sustained atrial flutter around the tricuspid valve in pigs: differentiation of procainamide (class IA) from flecainide (class IC) and their rate-dependent effects. $f$ Cardiovasc Pharmacol 1993;21:462-70.

8 Lab MJ. Contraction-excitation feedback in myocardium. Physiological basis and clinical relevance. Circ Res 1982; 50:757-66.

9 Kaseda S, Zipes DP. Contraction-excitation feedback in the atria: a cause of changes in refractoriness. $₹ \mathrm{Am}$ Coll Cardiol 1988;11:1327-36.

10 Klein LS, Miles WM, Zipes DP. Effect of atrioventricular interval during pacing or reciprocating tachycardia on interval during pacing or reciprocating tachycardia on
atrial size, pressure, and refractory period. Contractionatrial size, pressure, and refractory period. Contraction82:60-8.

11 Inoue $\mathrm{H}$, Matsuo $\mathrm{H}$, Takayanagi $\mathrm{K}$, Murao S. Clinical and experimental studies of the effects of atrial extrastimulaexperimental studies of the effects of atrial extrastimulation and rapid pacing on atrial flutter cycle. Evidence of 48:623-31.

12 Feld GK, Chen PS, Nicod P, Meyer DB, Fleck RP. Possible atrial proarrythmic effects of class Ic antiarrhythmic drugs. Am $\mathcal{F}$ Cardiol 1990;66:378-83. 